\title{
The East Flanders Prospective Twin Survey (Belgium): population-based register
}

\author{
Ruth Loos, Catherine Derom, Robert Vlietinck and Robert Derom \\ Katholieke Universiteit Leuven, Centre for Human Genetics, Belgium
}

\begin{abstract}
The East Flanders Prospective Twin Survey (EFPTS), started in 1964, is unique among the 17 major European twin registers because it is population based, the twins (and higher order births) are ascertained at birth, basic perinatal data are collected, chorion type is established and, when appropriate, genetic markers including DNA fingerprints, are determined. The total number of sets is 5089 twin, 158 triplet and 14 of higher order. Zygosity has been diagnosed on the basis of sex, placental structure and genetic markers in more than $95 \%$ of pairs. The EFPTS is the only large register that includes placental data and allows differentiation of three subtypes of monozygotic twins based on the time of the initial zygotic division: the dichorionic-diamnionic pairs (early), the monochorionic-diamnionic pairs (intermediate), and the monochorionic-monoamnionic pairs (late). Methodology and basic results in twins are considered in this article; detailed studies will be reported later. The sex proportion in dizygotic (DZ) twins is the same as in singl etons, whereas monozygotic (MZ) twins number more girls than boys. The difference in perinatal mortality between $D Z$ and $M Z$ twins is limited to the monochorionic $M Z$ subgroup. Birth weight is highest in $D Z$ twins and diminishes stepwise in $M Z$ dichorionic and $M Z$ monochorionic twins. Duration of pregnancy follows the same trend but is limited to a few days. Iatrogenic pregnancies are increasing to the point of representing almost 50\% of the twin births in 1997.
\end{abstract}

Keywords: twin, prospective, zygosity, placentation, chorionicity, population-based

\section{Introduction}

The East Flanders Prospective Twin Survey (EFPTS), started in 1964, is one of the 17 European twin registers reviewed recently. ${ }^{1}$ It is characterised by several features. For example it is population-based, prospective with the possibility of long-term followup, contains full perinatal data including placentation and is unique in the degree of accuracy of the zygosity determination.

'This initial communication focuses on the EFPTS' history, size and methodology. At birth, all types of multiple births have been identified, so that like-sex as well as opposite-sex twin pairs, and higher-order multiple births have been included. As a total of 5089 twin pairs, 158 triplets, 12 quadruplets, one set of quintuplets and one set of octuplets are captured in the database, only twin pairs will be considered in this article.

The study of human twins is frequent in biology, medicine and genetics. Nevertheless, twin research is subject to criticism on the basis of potential biases.

Correspondence: Ruth Loos, Katholieke Universiteit Leuven, Centre for Human Genetics, Herestraat 49 ON6, B-3000 Leuven, Belgium. Tel: +3216345896; Fax: + 3216345994 ; E-mail: ruth.loos@med.kuleuven.ac.be

Received 4 September 1998; accepted 9 November 1998
A particular problem of early twin studies is that generally they were small $I^{2}$ and often unrepresentative. Their inadequate statistical power has been recognised for two decades. ${ }^{3,4}$ Moreover, over-representation of monozygotic (MZ) and of concordant pairs is common. ${ }^{2}$ Self-reported series are a popular means of identifying twin cohorts with specific diseases, but self-selection may also cause a serious bias. Numerous studies present doubts about the accuracy of zygosity determination at a time where the need for accurate zygosity diagnosis is greater than ever ${ }^{5}$ with the increasing use of dizygotic (DZ) twins for quantitative trait loci (QTL) linkage. Finally, the classical twin method, on which most heritability estimates are based, assumes that the prenatal environment of twins is similar. This assumption is questioned by several investigators, ${ }^{6-8}$ who found more concordance between dichorionic pairs compared with monochorionic pairs. Aside from concordance, it is also clear that the assumption that the single MZ placenta is divided on a $50-50$ basis is totally incorrect. Some are, to be sure, but $60-40 ; 70-30$ and $80-20$ splits are al so seen.

The study of morphological features of the placenta may give us a better understanding of the role of the placenta as an environmental factor in determining foetal growth. ${ }^{9-12}$ Only large, populationbased twin registers with accurate zygosity diagnosis 
and good placentation data can provide reliable and unbiased estimates.

\section{Subjects and methods \\ Geographical characteristics}

The East Flanders Prospective Twin Survey was established on 15 July 1964 in the Province of East Flanders in Belgium. The province covers $10 \%$ of the surface of Belgium, and is inhabited by approximately $13 \%$ (1336000 inhabitants) of the Belgian population. The majority are of Caucasian origin and do not change place of residence frequently. As such, they are easily traceable, even after 34 years.

\section{Data collection}

In Belgium, over $99 \%{ }^{13}$ of mothers deliver in a maternity ward. In the case of multiple births this percentage is even higher. In East Flanders there are 20 maternity units (17000 births/year on average in the whole of the province). All obstetricians working in these units agreed to participate in the survey. Every multiple birth was reported to the EFPTS within 24 hours after the delivery. Within 24 hours after the notification of a delivery, a trained midwife visited the hospital and registered data in a standardised manner. All pairs of whom at least one of the children, live or stillborn, weighed $500 \mathrm{~g}$ or more and, when birth weights were unknown, gestation was at least 22 weeks, were entered into the register. Birth date and time, birth weight, parental ages and parity were obtained from the obstetric records. Identification data of the parents were registered in conformity with the law on protection of privacy.

Structured questionnaires (answered by the obstetrician and pediatrician) were used to provide information on the mode of conception, foetal presentation, mode of delivery, birth order, possible pathologies, ABO and Rh blood groups, heal th status of the mother before, during and after the delivery, and health and life status of the children for the period they stayed in the maternity unit. Gestational age, calculated as the number of completed weeks, was reported by the obstetrician.

\section{Examination of the placenta}

The umbilical cord was cut and ligated according to birth order in the maternity hospital. Placentas were collected and stored in the refrigerator in plastic bags until a trained midwife examined them in the laboratory, within 24 hours of the delivery. Foetal membranes were carefully dissected and placental weight, length, width and thickness were measured. Since 1992, however, the placentas of unlike-sexed twins without major pathology have no longer been examined.

According to the zygosity and the number and structure of the placental membranes, four groups of twins were distinguished:

1) dizygotic twins (DZ);

2) monozygotic dichorionic twins (MZ DC);

3) monochorionic diamnionic twins (MC DA); and

4) monochorionic monoamnionic twins (MC MA).

In DZ twins, who develop from the fertilisation of two ova, each embryo develops within its own membranes: all DZ pairs are therefore dichorionic (DC). In contrast, all monozygotic (MZ) twins arise from a single fertilised ovum. At some stage between the fertilisation and the formation of the embryonic disc, the formative material divides into two parts, each giving rise to a complete embryo. It is commonly believed that, if the division occurs at an early stage (before the 4 th day after conception ${ }^{14}$ ), each embryo of the resulting $M Z$ pair will have a separate set of membranes. The two embryos are dichorionic and, in this respect, resemble DZ twins. If, however, the division of the ovum is delayed until the blastocyst has formed (between day 4 and day 8 after conception ${ }^{14}$ ), the two embryos will share a single chorionic membrane but develop within two separate amnionic sacs. Such pairs are monochorionic, albeit diamnionic. Exceptionally, the division of the formative material may be delayed until the embryonic disc separates from the cavities that will subsequently form the amnionic and chorionic sacs (after implantation into the endometrium). ${ }^{14}$ When this happens the embryos will both share a single chorionic and amnionic sac. They are monochorionic monoamnionic.

Three types of placentas can be present in DC twins (DZ as well as MZ): two separate placentas, two placentas connected with membranes, and one fused placenta. In fused placentas, a clear dividing line between the two parts remains after removing the amnionic membranes. Where placentas were connected with membranes, the distance between the two placentas was measured. In separated DC placentas, the respective length, width and thickness were measured for each placenta. Only one placenta was present in almost all MC twins. After removing the membranes, any dividing line disappeared. The length, width and thickness were therefore measured for the placenta as a whole. The length of the placenta was defined as the longest diameter, and the width as the widest diameter orthogonal to the length diameter. A fresh, unfixed placenta was weighed after removing the membranes and blood 
clots. Since September 1969, a sample of all placentas has been taken and frozen at $-20^{\circ} \mathrm{C}$ for later determination of genetic markers if necessary.

The site of the cord insertion was noted and the distance between the two insertions was measured. Six categories of insertion were distinguished: central, eccentric, paramarginal, marginal, on the surrounding, and on the dividing membrane. Blood was taken from the umbilical cord if the blood groups of the twins had not been determined in the referring hospital. Cord length was measured, the number of umbilical arteries counted and knots and windings were recorded. Umbilical vessels of monochorionic placentas were injected to study placental vasculature and anastomoses. Because of financial stringency, this was performed only rarely between July 1975 and December 1985. An obstetrician (RD) examined placentas with suspected or obvious pathology. A distinction was made between foetal pathology such as infarctions, or torn lobes, and maternal pathology, such as deposition of fibrin and hydramnion. A full description of the examination of the placentas is given by Derom et al. ${ }^{15}$

\section{Zygosity diagnosis}

Zygosity was determined through sequential analysis in live and still births based on sex, foetal membranes, umbilical cord blood groups (ABO, Rh CcDEe, MNSs, Duffy, Kell), placental alkaline phosphatase, ${ }^{9,15,16}$ and DNA fingerprints. ${ }^{17-19}$ Unlikesexed twins and same-sexed twins with at least one different genetic marker were classified as DZ; monochorionic (MC) twins were classified as $M Z$. For all same-sexed DC twins with the same genetic markers a probability of monozygosity was calculated using a lod score method. ${ }^{16}$ After DNA fingerprinting, a probability of monozygosity of 0.999 is reached. Due to financial stringency, however, DNA fingerprints could not be determined on all twin pairs. Therefore, in this study, only same-sexed DC twins with the same markers, reaching a probability of 0.95 or more, was considered MZ. ${ }^{16}$ The remaining DC twins were classified as 'unknown'.

\section{Statistical analysis}

In the current analysis, three groups were compared: the dizygotic (DZ), the monozygotic dichorionic (MZ $D C)$ and the monozygotic monochorionic (MZ MC) pairs. Only twin pairs with a probability of accurate zygosity assessment of 0.95 or more were considered, including pairs with stillborn infants. The normality of the distributions of the continuous data was tested by the Shapiro-Wilk test. When data were normally distributed, groups were compared by parametric analysis of variance; otherwise the Krus-
kal-Wallis test was performed. The contingency $\chi^{2}$ test and, when appropriate, the Fischer exact test were used for comparisons of categorical data. When the $\chi^{2}$ appeared to be significant, odds ratios (OR) and their two-sided $95 \%$ confidence intervals $(\mathrm{Cl})$ were calculated to determine the strength of the association. For the sex-proportion in DZ twins, the proportion of male infants was considered, whereas in $M Z$ twins, the proportion of male pairs was considered. Foetal mortality was expressed as the proportion of all children in the survey who were stillborn; early neonatal mortality was the proportion of all live born children who died within 7 days of delivery; and perinatal mortality was the proportion of all children who were stillborn or died within 7 days. Because of the high correlation of the birth weights of both infants in a twin pair, we considered the mean birth weight ([birth weight twin $1+$ birth weight twin 2]/2) of each pair (not the individual birth weight of each infant). Total placental weight was defined as the weight of the placenta when both foetuses shared one placenta and the sum of the weight of both placentas if each foetus had its own placenta. Two separate placentas or two placentas connected by membranes were considered as two placentas, whereas one placenta or a fused placenta was counted as one placenta.

The analyses were conducted with the SAS6.12 computer package. All reported $\mathrm{P}$ values are twosided and were considered statistically significant when $\mathrm{P} \leq 0.05$. The Bonferroni correction was applied for multiple testing: since 13 tests were performed for comparing $D Z, M Z D C$ and $M Z M C$ pairs, only results with a $P$ value below 0.004 must be considered significant. The reported $\mathrm{P}$ values are the uncorrected ones.

\section{Results}

As of 31 December 1997, the EFPTS contained 5089 twin pairs. Forty-five pairs were excluded because neither infant weighed more than $500 \mathrm{~g}$, or because birth weight was unknown and gestational age was less than 22 weeks.

Zygosity was unknown $(P<0.95)$ for $277(5.5 \%)$ DC same-sex pairs. They too were excluded from further statistical analysis, leaving 4767 pairs with known zygosity. Of these, 3047 (64\%) were DZ. The remaining $36 \%$ were $M Z$, and of them $494(10 \%)$ were MZ DC and 1226 (26\%) MZ MC. Of the MZ MC twins, 41 pairs were monoamnionic, of whom three were Siamese pairs.

There were slightly more female than male (sex proportion of 0.482$) \mathrm{MZ}$ pairs. The sex proportion in DZ twins (0.512) was significantly higher than in $\mathrm{MZ}$ twins $(P=0.03, O R=1.13,95 \% \mathrm{Cl}=[1.01-1.25])$. 
Close to half ( $51 \%$ ) of the DZ pairs were of opposite sex. Of the remaining same-sexed pairs there were slightly more male than female pairs (Table 1 ).

In 42 deliveries both children were stillborn; in 126 deliveries one child was stillborn. In Figure 1 foetal, early neonatal and perinatal mortality is given according to the three groups: $D Z, M Z D C$ and $M Z$ MC. The mortality in both DC groups was comparable. MZ MC infants had a significantly $(P<0.001)$ higher risk of perinatal death compared with DZ twins.

The first twins born after infertility treatment were registered in 1976. Since then the rate of induced twins increased markedly (Figure2).

Of all twins, born after spontaneous conception, $M Z$ pairs were significantly more likely to be born to primipara than $\mathrm{DZ}$ pairs $(\mathrm{MZ} \mathrm{DC} \mathrm{OR}=1.8$ and $\mathrm{P}=0.001 ; \mathrm{MZ} \mathrm{MC} O \mathrm{OR}=1.2$ and $\mathrm{P}=0.004$ respectively) (Table2).

Table 3 describes the age of the parents, gestational age, mean birth weight and placental weight. Parents of $D Z$ twins were significantly older than $M Z$ parents $(P<0.001)$. Within the $M Z$ subgroups, $M Z D C$ and MZ MC, no parental age differences were found. Mean gestational age for DZ pairs (36.5 weeks) was on average 3 days longer $(P=0.007)$ than for $M Z M C$ pairs (36.1 weeks). No other differences in gestational age were found. The mean birth weight of $D Z$ pairs was on average $75 \mathrm{~g}$ more than that of $\mathrm{MZ}$ DC pairs $(P<0.001)$, who weighed $87 \mathrm{~g}$ more than the MZ MC pairs $(P<0.001)$. Placental weight of $D Z$ pairs was significantly higher $(21 \mathrm{~g}$ and $33 \mathrm{~g}$, respectively $\mathrm{P}<0.001$ ) than that of $\mathrm{MZ} \mathrm{DC}$ and $\mathrm{MZ} \mathrm{MC}$ pairs. No significant difference was found in both $M Z$ subgroups ( $M Z D C$ and $M Z M C)$, see Table 3 .

In both DC groups about half of the pairs had two placentas. This was only rarely seen in MZ MC pairs (Table4).

\section{Discussion}

Population-based registers are fundamentally different from volunteer samples. Kaprio et $\mathrm{al}^{20}$ have reviewed these differences in their description of the Scandinavian registers that can be considered as models for large-scale population-based surveys. The greatest advantage of such registers is undoubtedly the absence of selection biases as illustrated by the 'two thirds rule', ie the over representation of females in volunteer samples. ${ }^{21}$ We have added a new dimension to the Scandinavian model by collecting data on the pregnancy, the perinatal events, the placental structure and, when appropriate, genetic markers. The only other large-scale register with the same characteristics is the 'Birmingham Twin Survey' which unfortunately had to be discontinued soon after its launch owing to lack of funding.

The most recent 10 years EFPTS represent more than $98 \%$ of all twins born in that area and registered by the National Institute of Statistics. The EFPTS twin sample is also representative of the twin population of East Flanders with respect to maternal age, sex proportion, proportion of same sexed pairs, neonatal mortality, and frequency distribution of blood groups. ${ }^{16}$ The proportion of $\mathrm{DZ}$ and $\mathrm{MZ}$ pairs in our data, as well as the partitioning of the $M Z$ pairs according to chorionicity confirm previous findings in Caucasian populations. ${ }^{22-24}$

$M Z$ pairs show a lower sex proportion compared with DZ twins whose sex proportion is the same as that of singletons. The difference is of borderline statistical significance. Analysing pooled data, James ${ }^{25}$ estimated the sex proportion of $M Z$ twins at 0.499. As he admitted, however, the evidence was inconclusive. In our data, it is even lower, at 0.482 . Considering the results of both our study and that of James, it is safe to state that the majority of $\mathrm{MZ}$ twins are probably female. The ratio of same-sex to opposite sex pairs found in DZ twins is roughly in accordance with the Weinberg ${ }^{26}$ rule as reported earlier by our group. ${ }^{27}$ How ever, our data do not rule out subtle secular changes in that proportion as suggested by ames $^{28}$ and Orlebeke et al. ${ }^{29}$ To solve the controversy, one should analyse populationbased data in which the probability of zygosity should be at least 0.999 . This discussion is not

Table 1 Number of twin pairs according to sex, zygosity and chorionicity

\begin{tabular}{|c|c|c|c|c|c|c|c|c|c|c|}
\hline & \multicolumn{2}{|c|}{$\mathrm{DZ}$} & \multicolumn{2}{|c|}{ MZDC } & \multicolumn{2}{|c|}{ MZMC } & \multicolumn{2}{|c|}{$\mathrm{MZ}$ total } & \multicolumn{2}{|c|}{ Unknown } \\
\hline & $\mathrm{n}$ & $\%$ & $\mathrm{n}$ & $\%$ & $\mathrm{n}$ & $\%$ & $\mathrm{n}$ & $\%$ & $\mathrm{n}$ & $\%$ \\
\hline Male pairs & 779 & 26 & 238 & 48 & 591 & 48 & 829 & 48 & 145 & 52 \\
\hline Female pairs & 708 & 23 & 256 & 52 & 635 & 52 & 891 & 52 & 132 & 48 \\
\hline $\begin{array}{l}\text { Unlike-sexed } \\
\text { pairs }\end{array}$ & 1560 & 51 & - & & - & & - & & - & \\
\hline Total & 3047 & $\begin{array}{r}100 \\
64\end{array}$ & 494 & $\begin{array}{r}100 \\
10\end{array}$ & 1226 & $\begin{array}{r}100 \\
26\end{array}$ & 1720 & 100 & 277 & 100 \\
\hline
\end{tabular}

$\mathrm{n}=$ number of pairs 
purely academic, because the Weinberg rule is the major tool available for the study of trends in $M Z$ and DZ twinning rates when zygosity is not known. The Weinberg rule has been criticised frequently and with good cause.

Since 1976 the increase in the number of births following infertility treatment has been unremitting. In 1993 Derom et al $^{30}$ expressed concern about the consequences of this epidemic with respect to public heal th. Despite this, the increase has been even more pronounced since 1990 and, in 1996 and 1997, almost half the yearly number of all twin pairs were born after infertility treatment.
Confirming a preliminary report, ${ }^{31} \mathrm{MZ} \mathrm{MC}$ infants are at a significant higher risk of dying perinatally than DZ infants, especially before birth, whereas MZ $D C$ infants have the same risk as DZ infants. This observation indicates that perinatal mortality is more a matter of chorionicity than zygosity, which is in agreement with the findings of Neilson et al. ${ }^{32}$

There has been criticism on the classical twin studies with regard to the circumstances of $M Z$ twin gestation. In an often quoted paper, Price $^{33}$ reviewed the antenatal and natal difference-producing factors in $M Z$ pairs. The most important of these is undoubtedly chorionicity. Other factors, however, must also

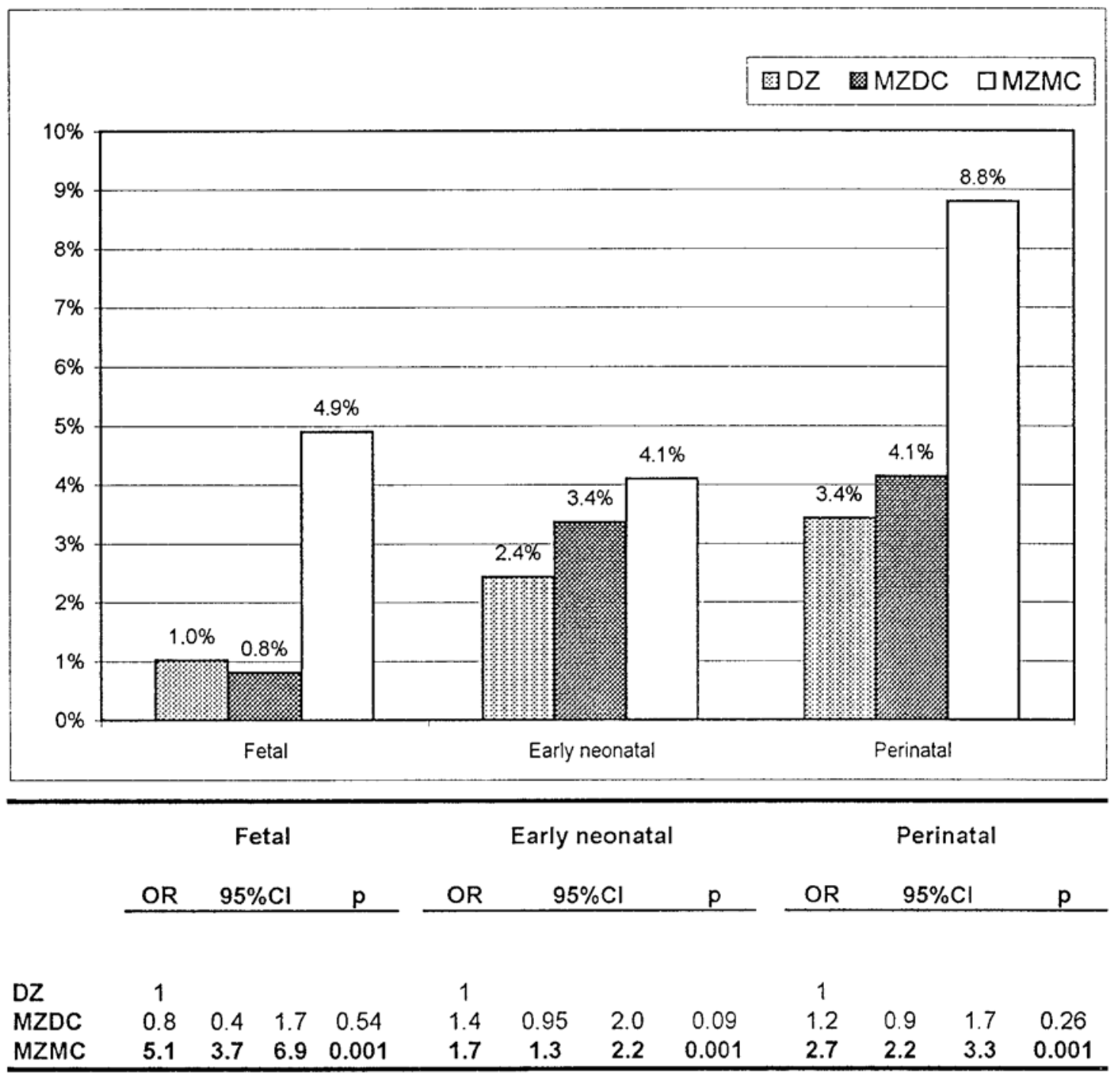

"MZDC and MZMC infants are compared to $D Z$ infants $(O R=1)$

OR: odds ratio

95\% Cl: $95 \%$ confidence interval

p: probability

Figure1 Foetal, early neonatal and perinatal mortality rates of DZ, DCMZ and MC infants with corresponding odds ratios 


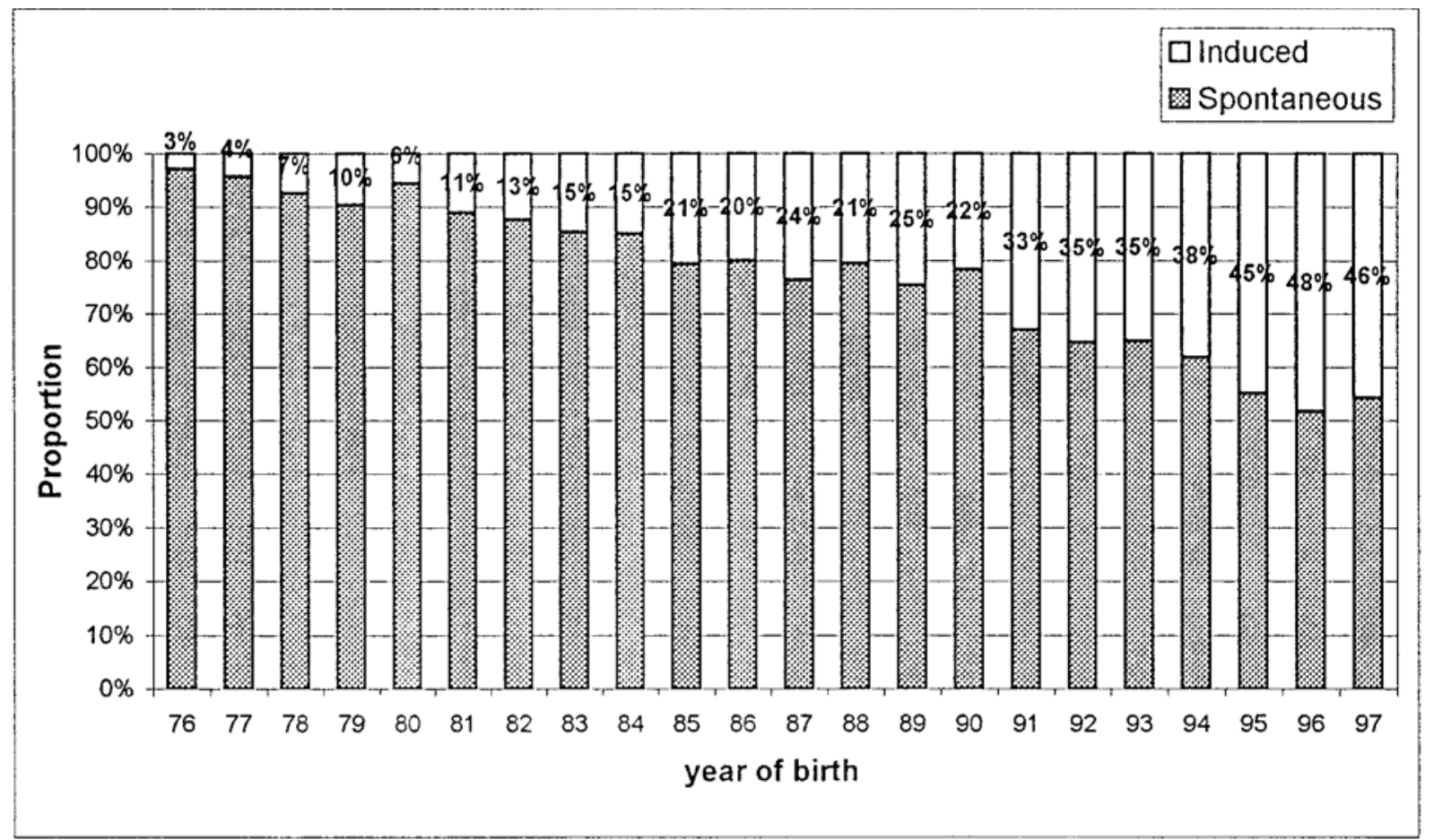

Figure 2 Proportion of induced and spontaneous twin maternities by year of birth

Table 2 Primiparity of spontaneously conceived twin pairs

\begin{tabular}{lllllll}
\hline & $\mathrm{n}$ & $\%$ & $\mathrm{OR}^{\mathrm{a}}$ & $95 \% \mathrm{Cl}$ & $\mathrm{P}$ \\
\cline { 2 - 6 } DZ & 844 & 40.0 & 1 & & & \\
MZDC & 260 & 54.2 & 1.8 & 1.5 & 2.2 & 0.001 \\
MZMC & 530 & 45.2 & 1.2 & 1.1 & 1.4 & 0.004 \\
\hline
\end{tabular}

$\mathrm{n}=$ numbers of pairs; OR: odds ratio; ${ }^{\mathrm{a}} \mathrm{MZDC}$ and MZMC pairs are compared with $\mathrm{DZ}$ pairs $(\mathrm{OR}=1)$; $\mathrm{Cl}$ : confidence interval be considered: gestational age, birth sequence, birth weight and, in those twins born vaginally, the presentation of both twins (cephalic, breech, transverse). Price ${ }^{33}$ concludes: 'It would seem to follow that part of the time and effort which will doubtless be expended on research with twins in the next decade or two could well be spent on identifying twin pregnancies two months or more before term, and obtaining much more complete information than we now possess as to the effects of prenatal and

Table 3 Age of the parents, gestational age, mean birth weight and placental weight (mean and SD)

\begin{tabular}{|c|c|c|c|c|c|c|c|c|c|c|c|}
\hline \multirow[b]{3}{*}{ Age of mother (years) } & & \multicolumn{3}{|c|}{$\mathrm{DZ}$} & \multicolumn{3}{|c|}{ MZDC } & \multicolumn{2}{|c|}{ MZMC } & \multirow{2}{*}{\multicolumn{2}{|c|}{ significance $(P)$}} \\
\hline & & mean & & SD & mean & & SD & mean & SD & & \\
\hline & & 28.4 & & 4.6 & 26.6 & & 4.6 & 27.1 & 4.7 & $<0.001$ & $\mathrm{DZ}>\mathrm{MZDC}, \mathrm{MZMC}$ \\
\hline & $\mathrm{n}$ & & 2998 & & & 482 & & & & & \\
\hline \multirow[t]{2}{*}{ Age of father (years) } & & 30.8 & & 5.4 & 29.2 & & 5.3 & 29.4 & 5.3 & $<0.001$ & $\mathrm{DZ}>\mathrm{MZDC}, \mathrm{MZMC}$ \\
\hline & $\mathrm{n}$ & & 2418 & & & 408 & & & & & \\
\hline \multirow[t]{2}{*}{ Gestational age (weeks) } & & 36.5 & & 2.8 & 36.2 & & 3.0 & 36.1 & 3.4 & $<0.01$ & $D Z>M Z M C$ \\
\hline & $\mathrm{n}$ & & 2685 & & & 429 & & & & & \\
\hline \multirow[t]{2}{*}{ Mean birth weight (gm) } & & 2476 & & 512 & 2401 & & 562 & 2314 & 559 & $<0.001$ & $\mathrm{DZ}>\mathrm{MZDC}>\mathrm{MZMC}$ \\
\hline & $\mathrm{n}$ & & 3030 & & & 494 & & & & & \\
\hline \multirow[t]{2}{*}{ Placental weight (gm) } & & 471 & & 161 & 720 & & 167 & 708 & 164 & $<0.001$ & $\mathrm{DZ}>\mathrm{MZDC}, \mathrm{MZMC}$ \\
\hline & $\mathrm{n}$ & & 2639 & & & 479 & & & & & \\
\hline
\end{tabular}

$\mathrm{n}=$ number of pairs 
natal factors in the two types of MZ pairs. The results of such a study might show that the twin method, as ordinarily applied, is too crude for purposes of modern nature-nurture studies. At the same time, pairs of monochorionic type might prove to be of more interest and value for theoretical problems of developmental genetics than is commonly supposed'. Regrettably, despite Benirschke's ${ }^{34}$ plea, Price's expectation has not materialised.

It is assumed, with reason, that the division of the zygote occurs earlier in DC than in MC pairs. ${ }^{34,35}$ Leroy, ${ }^{36}$ referring to observations of non-human mammals, argues that early division of the zygote, say at the 2-8 cell stage, is highly improbable because the zona pellucida is, at that time, intact. Other observations, also in non-human mammals, demonstrate the possibility of duplication of the blastocyst. ${ }^{37}$ The dispute has been settled by studying $X$-inactivation in $M Z$ female pairs. If $\mathrm{X}$-inactivation is symmetrical in MC pairs and asymmetrical in DC pairs, then the commitment to $\mathrm{X}$-inactivation must occur before the blastocyst stage. This is indeed the case as shown by Monteiro et $\mathrm{al}^{38}$ who estimate that the commitment occurs around the 16-cell stage. It is thus confirmed that the timing of twinning must be considered as an additional important variable in twin studies. ${ }^{39}$

A sizeable group of some 500 dichorionic $M Z$ twins (study in progress) will enable us to perform classical twin studies with no bias, based on the crucial assumption that $M Z$ and $D Z$ twins have a similar intrauterine environment. Admittedly, there is a small but significant mean birth weight difference of $75 \mathrm{~g}$ in favour of the DZ pairs, a difference which is much smaller than reported in previous studies in which MC pairs were compared with DC pairs, a heterogeneous group of $M Z$ and $D Z$ twins. ${ }^{6}$ It remains to be seen if this difference entails any biological consequences.

Both parents of twins and referring obstetricians and pediatricians have appreciated our reports on placentation and zygosity. The success of the survey, which now covers almost $100 \%$ of the multiples born in the province, is for a great part due to the service rendered to the community of the multiples and their health care providers. Also, multiples and

Table 4 Number and percentage of twin pairs with one and two placentas

\begin{tabular}{ccccccc}
\hline & \multicolumn{2}{c}{$\mathrm{DZ}$} & \multicolumn{2}{c}{ MZDC } & \multicolumn{2}{c}{ MZMC } \\
& 1 & 2 & 1 & 2 & 1 & 2 \\
\hline $\mathrm{n}$ & 1483 & 1549 & 264 & 228 & 1217 & 9 \\
$\%$ & 49 & 51 & 54 & 46 & 99 & 1
\end{tabular}

$\mathrm{n}$ : number of pairs; 1 = one or one fused placenta; 2 = two separate placentas or two placentas connected with membranes their families have rightly become more vocal about zygosity determination. The Council of Multiple Birth Organization of the International Society for Twin Studies ${ }^{40}$ has developed a "Declaration of Rights and Statement of Needs of Higher Order Multiples" in which it is stated that "Parents have a right to expect accurate recording of placentation and the diagnosis of the zygosity of same sex multiples at birth."

EFPTS, though of small size, is unique and should be of great help to highlight some of the basic merits of classical twin studies. As stated by Martin et al, ${ }^{5}$ 'there are few twin resources with good placentation data and adult phenotypes for comparison, so such effects remain to the field of speculation. However, investment in such a resource is likely to yield rich rewards in our understanding of developmental etiology'.

We believe, as do others, ${ }^{5}$ that we are on the threshold of an exciting new era of twin research directed at a refined methodology of the classic twin study, a better knowledge of what makes MZ twins different, and a better genetic analysis of complex traits. Accurate determination of placentation and zygosity is a prerequisite to attaining these goals.

This paper gives only an overview of the very basic results of the survey. More detailed analyses of the East Flemish twins will deal with birth weight, perinatal mortality, congenital anomalies, iatrogenic pregnancies and the Weinberg rule.

\section{Acknowledgements}

Since its origin, the EFPTS has been partly supported by grants from the Fund of Scientific Research, Flanders (Bel gi um) and by the Association for Scientific Research in Multiple Births (Bel gium). We are grateful to all the East Flemish maternity units for their co-operation, to the gynaecologists, $M$ Bafort, S Balliu, P Bafort, C Beghin, A Bellens, C Bockaert, P Boelens, A Cammaert, J Caudron, T Coetsier, C Colmant, G Cooreman, J Daels, M-C Dall equin, A De Bruyn, G Debruyne, W Decleer, K De Cleyn, A De Craene, P Defoort, M De Geest, H De Gezelle, R De Haan, K De Ketelaere, P De Maesschalck, E De Mot, V Depauw, H Depypere, D De Schryver, A De Smet, $P$ De Sutter, A De Vits, $P$ Devroey, $\mathrm{N}$ Dhondt, $\mathrm{M}$ Dhont, $\mathrm{F}$ Dumortier, $\mathrm{W}$ Flamee, G Ghesquiere, R Goethals, F Hauspy, S Hellebaut, A-M Hendrickx, T Hennay, R Heughebaert, R Heydanus, S Heylen, F Ingel s, G Janssens, J Janssens, J Landuyt, J Leemans, L Londers, $H$ Loobuyck, I Martens, R Meersseman, G Meganck, E Merchiers, JMerveille, G Mestdagh, L Montauban, P 
Mulier, H Nagels, S Nuradi, G Onghena, A Ooms, D Oosterlynck, G Orye, P Pardon, W Parewijck, P Pattyn, P Peeters, H Peli caen, JRappe, G Romelart, A Saey, P Santens, A Seghers, E Serreyn, R Serreyn, D Smet, J Smolders, D Spinnewijn, M Struyven, M Temmerman, E Termont, L Teughels, B Thaler, M Thiery, $P$ Van Baelen, $P$ Van Damme, B Vandaele, D Van den Broecke, $\mathrm{R}$ Van den Broecke, J Van den Haute, R Van den Haute, K Vanderheyden, E Vandevelde, J Van Ginderachter, E Van Herzeele, G Van Hoecke, G Van Hoorde, $\mathrm{H}$ Van Kets, A Van Parijs, $P$ Van Trappen, G Verbeke, L Verbeke, C Vereecke, N Verhoeven, G Verhulst, M Verpoest, G Verstraete, P Verstraeten, M Volckaert, M Vrijens, R Walckiers, A Waterschoot, R Weckhuysen, S Weyers, T Wirawan, K Witters, I Yo Le Sian, R Zweers; to the midwives, C Bastiaen, I Berkmoes, C Bracke, F Cormenier, K De Baere, G Demaeyer, M-C De Pue, R De Smet, K Reyniers; G Vossaert for the fieldwork, and to our late secretary, D Celen. Ruth Loos is supported by grants from the Fund of Scientific Research, Flanders (Belgium). We are especially grateful to Louis G Keith who has edited the manuscript.

\section{References}

1 Boomsma D. Twin registers in Europe: an overview. Twin Research 1998; 1: 34-51.

2 Bundey S. Uses and limitations in twin studies. JNeurol 1991; 238: 360-364.

3 Martin N, Eaves LJ, Kearsey MJ, Davies P. The power of a classical twin study. Heredity 1978; 40: 97-116.

4 Neale M, Eaves LJ, Kendler KS. The power of the classical twin study to resolve variation in threshold traits. Behav Genet 1994; 24: 239-258.

5 Martin N, Boomsma D, Machin A. A twin-pronged attack on complex traits. Nat Genet 1997; 17: 387-392.

6 Phillips DIW. Twin studies in medical research: can they tell us whether diseases are genetically determined? Lancet 1993; 341: 1008-1009.

7 Gruenwald P. Environmental influences on twins apparent at birth: a preliminary study. Biol Neonate 1970; 15: 79-93.

8 Machin G. Some causes of genotypic and phenotypic discordance in monozygotic twin pairs. Am J Med Genet 1996; 61: 216-228.

9 Derom R, Vlietinck R, Derom C, Keith LG, Van den Berghe H. Zygosity determination at birth: a plea to the obstetrician. J Perinat Med 1991; 19: 234-240.

10 Fisk NM, Bryan EM. Routine prenatal determination of chorionicity in multiple gestation: plea to the obstetrician. $\mathrm{Br}$ J Obstet Gynaecol 1993; 100: 975-977.

11 Allen C, Raafat F, Morgan I. Routine prenatal determination of chorionicity in multiple gestation: a plea to the obstetrician. $\mathrm{Br}$ J Obstet Gynaecol 1994; 101: 829-.

12 Denbow ML, Fisk NM. Fetal testing in twins. Curr Opin Obstet Gynecol 1997; 9: 96-101.

13 Bekaert A, Martens G, Devliegher H, Amy J. Perinatale activiteiten in Vlaanderen 1997 (Perinatal activities in Flanders), Studiecentrum voor Perinatale Epidemiologie (SPE): Jaarverslag: Brussel, 1998.
14 Bulmer MC. The Biology of Twinning. Oxford University Press: London, 1970.

15 Derom R, Derom C, Vlietinck R. Placentation. In: Keith LG, Papiernik E, Keith DM, Luke B (eds). Multiple Pregnancy: Epidemiology, Gestation and Perinatal Outcome. 1st edn. Parthenon Publishing: New York, 1995, pp 113-132.

16 Vlietinck R. Determination of the zygosity of twins. Dissertation. K.U. Leuven, 1986.

17 Derom C, Bakker E, Vlietinck R, Derom R, Thiery M, Pearson P. Zygosity determination in newborn twins using DNA variants. J Med Genet 1985; 22: 279-282.

18 Derom C, Vlietinck R, Derom R, Boklage C, Thiery M, Van den Berghe H. Genotyping macerated stillborn fetuses. Am JObstet Gynecol 1991; 164: 797-800.

19 Decorte R, Cuppens H, Marijnen P, Cassiman J. Rapid detection of hypervariable regions by the polymerase chain reaction technique. DNA Cell Biol 1990; 9: 461-469.

20 Kaprio J, Koskenvuo M, Rose RJ. Population-based twin registries: illustrative application in genetic epidemiology and behavioral genetics from the Finnish Twin Cohort Study. Acta Genet Med Gemellol (Roma) 1990; 39: 427-439.

21 Lykken D, Tellegen A, DuRubeis R. Volunteer bias in twin research: The rule of two thirds. Soc Biol 1978; 25: 1-9.

22 Benirschke K, Kim CK. Multiple pregnancy. N Engl J Med 1973; 288: 1276-1284.

23 Bleker OP, Breur W, Huidekoper BL. A study of birth weight, placental weight and mortality of twins as compared to singletons. Br J Obstet Gynaecol 1979; 86: 111-118.

24 Robertson EG, Neer KJ. Placental injection studies in twin gestation. Am J Obstet Gynecol 1983; 147: 170-173.

25 James WH. Sex ratio and placentation in twins. Ann Hum Biol 1980; 7: 273-276.

26 Weinberg W. Beiträge zur Physiologie und Pathologie der Mehrlingsgeburten beim Menschen. Pflügers Arch Physiol Mensch Tier 1902; 88: 515-516.

27 Vlietinck R, Derom C, Derom R, Van der Berghe H, Thiery M. The validity of Weinberg's rule in the East Flanders Prospective Twin Survey (EFPTS). Acta Genet Med Gemellol (Roma) 1988; 39: 27-30.

28 James WH. The current status of Weinberg's differential rule. Acta Genet Med Gemellol (Roma) 1992; 41: 33-42.

29 Orlebeke J, Eriksson AW, Boomsma DI, Vlietinck R, Tas FJ, de Geus EC. Changes in the DZ unlike/like sex ratio in the Netherlands. Acta Genet Med Gemellol (Roma) 1991; 40: 319-323.

30 Derom C, Maes H, Derom R, Van den Berghe H, Vlietinck R. latrogenic multiple pregnancies in East Flanders, Belgium. Fertil Steril 1993; 60: 493-496.

31 Derom R, Vlietinck R, Derom C, Thiery M, Van Maele G, Van den Berghe $H$. Perinatal mortality in the East Flanders Prospective Twin Survey. Preliminary results. Eur J Obst Gynecol Reprod Biol 1991; 41: 25-26.

32 Neilson J, Danskin F, Hastie SJ. Monozygotic twin pregnancy: diagnostic and Doppler ultrasound studies. $\mathrm{Br} \mathrm{J}$ Obstet Gynaecol 1989; 96: 1413-1418.

33 Price B. Primary biases in twin studies. A review of prenatal and natal difference-producing factors in monozygotic pairs. Am JHum Genet 1950; 2: 293-352.

34 Benirschke K. Accurate recording of twin placentation. A plea to the obstetrician. Obstet Gynecol 1961; 18: 334-347.

35 Corner GW. Observed embryology of human single-ovum twins and other multiple births. Am JObstet Gynecol 1955; 70: 933-951.

36 Leroy F. Early embryology and placentation of human twins. In: Dulbecco R (ed). Encyclopedia of Human Biology. Academic Press: New York, 1991, pp 305-315.

37 Massip A, van der Zwalmen P, Mulnard W. Atypical hatching of cow blastocyst leading to separation to complete twin half blastocysts. Vet Rec 1983; 112: 301. 
East Flanders Prospective Twin Survey

$\mathrm{R}$ Loos et al

38 Monteiro V, Derom C, Vlietinck R, Kohn N, Lesser $M$, Gregerson PK. Commitment to $\mathrm{X}$-inactivation precedes the twinning event in monochorionic MZ twins. Am JHum Genet 1998; 63: 339-346.
39 Puck $\mathbb{M}$. The timing of twinning: more insights from X-inactivation. Am JHum Genet 1998; 63: 327-328.

40 Declaration of Rights and Statement of Needs of Twins and Higher Order Multiples. Twin Research 1998; 1: 52-55. 